\title{
COMPARATIVE GENE EXPRESSION STUDY TO IDENTIFY GENES POSSIBLY RELATED TO STORAGE ROOT FORMATION IN CASSAVA
}

\author{
*Cláudia Regina Batista de Souza ${ }^{1,2}$, Luiz Joaquim Castelo Branco Carvalho ${ }^{1}$ and Júlio Cézar de \\ Mattos Cascardo ${ }^{3}$
}

\begin{abstract}
${ }^{1}$ EMBRAPA- Recursos Genéticos e Biotecnologia, Parque Estação Biológica- PqEB, Caixa postal 02372, Brasilia-DF, Brazil 70770-900. ${ }^{2}$ Current Address: Universidade Federal do Pará (UFPA), Rua Augusto Correa n. 01, Centro de Ciências Biológicas, Departamento de Genética, Guamá, Belém-PA, Brazil, 66075110. ${ }^{3}$ Universidade Estadual de Santa Cruz (UESC), Laboratório de Genomica e Expressão Gênica, Ilhéus-BA, Brazil, 45650-000. *Corresponding author: E-mail: bsouza@ufpa.br
\end{abstract}

\begin{abstract}
Cassava storage roots result from swelling of adventitious roots by secondary growth. In the present study we aimed to gain insight into the molecular processes occurring during cassava storage root formation. We report a comparative gene expression study in adventitious and storage roots in order to identify genes possibly related to storage organ formation. Our results revealed five genes with higher expression levels in secondary xylem of storage roots than adventitious roots. Among them, the Mec1 gene coding for Pt2L4 glutamic acid-rich protein and a putative RING Zinc Finger and LEA protein genes were strongly induced in secondary xylem tissue.
\end{abstract}

Keywords: cassava, comparative analysis, gene expression, Pt2L4 protein, secondary growth, storage root formation.

\section{INTRODUCTION}

Cassava (Manihot esculenta Crantz) is one of the most important food crops in the tropics and with respect to calories, ranks fourth, after rice, maize and sugarcane [1]. In developing countries cassava roots are very often the primary source of calories. Cassava roots contain about $85 \%$ starch and only about $1-2 \%$ of proteins [2].

The cassava storage root results from swelling of adventitious roots by secondary growth. Anatomical studies of the cassava storage root have been reported [3, 4] and we have suggested a model of storage root tissue organization, suitable for gene expression analyses [5]. This model describes three tissue systems: System I is composed of phellogen and phelloderm, System II of phloem and vascular cambium, and System III of secondary xylem with its highly specialized parenchymatic cells packed with starch granules [6]. Protein polymorphism of adventitious and storage roots of cassava have been studied in a 2-D gel system and the results showed over 260 proteins unique to the storage root and possibly related to secondary growth [7]. Studies to isolate and characterize cassava storage root protein genes were initiated by our group $[6,8,9,10]$. In these studies we identified an $18 \mathrm{kDa}$ protein with high identity to the small heat shock class of proteins and an alcohol-soluble protein similar to allergenic Hev b5 from the rubber tree, designated Pt1L4 and Pt2L4, respectively $[6,8,9]$. Expression analyses suggested that Pt2L4 is possibly related to the secondary growth pattern of cassava storage root since the level of Mec1 transcripts 
increases during the maturation of the secondary xylem and its parenchyma derived cells $[6,8,9]$. Recently a promoter of a cassava gene related to the Mec1 gene was isolated and the expression pattern in transgenic plants showed that this promoter is active in phloem, cambium and xylem vessels and is related to cassava storage root formation [11]. In sweet potato, another underground storage organ, genes possibly related to storage root induction were recenly identified by You et al. [12].

In this study we report a comparative gene expression analyses in adventitious and storage roots of cassava of order to identify genes related to storage organ formation. Storage root formation involves continuous elongation (primary growth) and radial growth. The cells of vascular cambium, a meristematic tissue, rapidly divide and expand resulting in secondary growth that increases root diameter. Secondary phloem is pushed to the outside and secondary xylem to the inside with parenchymatic cells that accumulate starch [5]. Theses characteristics of storage root formation are also common features found in the stem growth of forest trees, nodulation/tumorigenesis-related tissue and tuber development. Based on several molecular and cellular processes that would potentially occur during storage root formation, previously identified cassava genes (unpublished data) were functionally categorized and evaluated by comparative gene expression analysis. Results revealed five genes with higher expression levels in the in secondary xylem of storage roots than adventitious roots. Among them, the Mec1 gene coding for Pt2L4 glutamic acid-rich protein and a putative RING Zinc Finger and LEA protein genes were strongly induced in secondary xylem tissue. The putative function of these genes in storage organ formation is discussed.

\section{MATERIAL AND METHODS}

\section{Plant Material}

Adventitious roots were induced from IAC 12-829 cultivar stem cultivation and harvested fifteen days after. Secondary xylem tissue samples were isolated from storage roots with a diameter of $2 \mathrm{~cm}$, as described previously $[5,6]$.

\section{Comparative Analysis And Functional Identification}

Cassava gene sequences obtained previously (unpublished data) were aligned to the GeneBank nucleotide sequence databank using the BlastX algorithm with E-value cut off at 0.027 or lower. Based on the BlastX comparison results, cassava genes were identified according to their predicted function and used as probes in comparative gene expression analysis. Predicted protein sequences were analyzed by Conserved Domain Search program from NCBI.

\section{Northern Blot Analyses}

Total RNA from adventitious and storage roots of cassava were isolated as described previously [8]. Samples containing ten micrograms of RNA were separated on formaldehyde-agarose gels, transferred to Hybond $\mathrm{N}^{+}$membranes (Amersham) and hybridized with ${ }^{32} \mathrm{P}$-dCTP labeled probes (Pharmacia "Ready-to-go DNA Labeling kit). Hybridization was performed in 5X SSPE (SSPE: $150 \mathrm{mM} \mathrm{NaCl} ; 10 \mathrm{mM} \mathrm{NaH}_{2} \mathrm{PO}_{4} \mathrm{H}_{2} \mathrm{O}$; $1 \mathrm{mM} \mathrm{Na}{ }_{2} \mathrm{EDTA}_{2} \mathrm{H}_{2} \mathrm{O}$ ), $5 \mathrm{X}$ Denhardt's solution (Denhardt's solution: $0.02 \%$ (w/v) ficoll, $0.02 \%$ (w/v) PVP, 
$0.02 \%(\mathrm{w} / \mathrm{v}) \mathrm{BSA}$ ), $0.5 \%(\mathrm{w} / \mathrm{v}) \mathrm{SDS}$ and $0.1 \mathrm{mg} \mathrm{mL}^{-1}$ salmon sperm DNA at $60^{0} \mathrm{C}$ overnight. The blots were washed in 2 X SSPE $0.1 \%(\mathrm{w} / \mathrm{v})$ SDS, 1 X SSPE $0.1 \%(\mathrm{w} / \mathrm{v})$ SDS and $0.1 \mathrm{X}$ SSPE $0.1 \%(\mathrm{w} / \mathrm{v})$ SDS. All washings were performed at $60^{\circ} \mathrm{C}$ for 45 minutes each.

\section{RESULTS AND DISCUSSION}

In the present work we aimed to gain insight into the molecular processes occurring during cassava storage root formation. Identifying genes that are expressed during secondary growth will help elucidate molecular processes related to the development of parenchyma cells which accumulate starch and carotenoids. Specific promoter and enhancers of these genes can be used to drive efficient storage root specific expression.

Table 1: Cassava storage root sequences used as probes in comparative gene expression analysis.

\begin{tabular}{|c|c|c|c|c|}
\hline Acession number & Putative function & Organism & $\begin{array}{c}\text { Reference at } \\
\text { NCBI }\end{array}$ & E-value $^{\mathbf{b}}$ \\
\hline AY101376 & Secondary growth & Manihot esculenta & AAP57707 & $1 \mathrm{e}-38$ \\
\hline MALC01-D06 & RING Zinc Finger protein (RZF) & Arabidopsis thaliana & AAM67030 & $1 \mathrm{e}-25$ \\
\hline MAGL02H05 & MYB transcription factor protein & Malus xiaojinensis & AA045179 & $6 \mathrm{e}-49$ \\
\hline MALC02F04 & Calmodulin & Arabidopsis thaliana & NP189967 & $9 \mathrm{e}-80$ \\
\hline MALC01A10 & Extensin & Populus nigra & T09546 & 0.027 \\
\hline MALC01F09 & Translationally Controlled Tumour Protein \\
(TCTP) & Hevea brasiliensis & Q9ZSW9 & $9 \mathrm{e}-35$ \\
\hline MALC01B02 & Auxin Regulated protein (ARP) & Glycine max & T05726 & $2 \mathrm{e}-29$ \\
\hline MALC04-C04 & Protein induced upon tuberization (TUB) & Solanum demissum & CAA66948 & $6 \mathrm{e}-14$ \\
\hline MAGL02B05 & 14-3-3 protein & Nicotiana tabacum & O49997 & $6 \mathrm{e}-42$ \\
\hline
\end{tabular}

${ }^{a}$ Organism that showed the high identity with corresponding clone.

${ }^{\mathrm{b}}$ E-value released in June, 2004.

Based on the Blast $\mathrm{X}$ results, the cassava genes were categorized according to their predicted function. We selected candidate sequences related to different cellular and molecular processes that are most likely involved in storage root formation (Table 1). These sequences were deposited in Embrapa-Cenargen Genebank (Brasilia-DF, Brazil) and used as probes in comparative Northen Blot analysis. The Mec1 gene (AY101376) was also included in this study, since previous results indicated that this gene is related to secondary growth in storage root $[6,8,9]$. 


Gene AR / SR
Mec1
Ring Zinc Finger
Tuberization
TCTP
Calmodulin
Extensin
MYB
14.3 .3
ARP
RNA 28S

Figure 1. Comparative gene expression study of cassava adventitious roots (AR) and secondary xylem tissues from storage roots (SR) by Northern blot analysis. Samples containing about $10 \mu \mathrm{g}$ of total RNA were separated on formaldehyde-agarose gel, transferred to membranes and hybridized with radio-labeled probes as described in Material and methods. Ethidium bromide stained agarose gel with a ribosomal RNA sample was included as a quantitative control.

Our results showed that transcription of five cassava genes was higher in secondary xylem tissues of storage roots than adventitious roots (Figure 1). Transcription of the Mec1 and putative RING Zinc Finger and LEA genes was strongly induced in secondary xylem tissues (Figure 1). A highly induced expression of Mec1 in storage root was expected since previous results showed this gene to be related to secondary growth and storage root formation $[6,8,9]$. Another cassava protein with active expression in vascular system is the C54 which has high identity to Pt2L4 [11]. The functional role of Pt2L4 protein in secondary growth of cassava storage roots needs to be elucidated by further experiments. Transcription of a putative cassava RING zinc finger protein was also high in the storage root. The RING finger is a zincbinding domain that is found in proteins from a variety of species. Although the biological function of these proteins remains elusive, many of the RING zinc finger gene products have significant roles during development. Since a putative conserved domain of E3 ubiquitin ligase was detected in the cassava Ring Zinc Finger protein, it is possible that this protein is a proteassome regulatory subunit that plays a role in posttranslational modification and the protein turnover processes during storage root formation. However, 
the role of this gene in storage root formation remains to be investigated. Our results showed that cassava protein homologue to tuberization protein from Solanum demissum contains a typical domain of LEA (Late Embriogenesis Abundant) proteins. Many LEA proteins have been isolated from different plant species and they are related to dehydration and $\mathrm{ABA}$ induction processes.

For putative Translationally Controlled Tumour Protein (TCTP) and calmodulin cassava genes, hybridization signals were detected in RNA samples from both root types, however they were higher in secondary xylem tissues than in adventitious roots (Figure 1). TCTP is a highly conserved protein that is widely expressed in all eukaryotic organisms. TCTPs are highly regulated both at the transcriptional and translational levels by a range of extracellular signals and have been implicated in important cellular process, such as cell growth, cell cycle progression and apoptosis [13]. The only molecular functions of the TCTP identified so far are the tubulin-binding region and the $\mathrm{Ca}^{2+}$-binding site $[14,15]$. The putative cassava TCTP is homologue to HevTCTP protein which is expressed abundantly in latex from rubber trees. Since latex is also found in the cassava storage root, TCTP could have a function related to lacticiferis vessels formation. However, we have no information about the presence of latex in adventitious roots. Studies about wood-forming tissues of poplar identified a TCTP sequence expressed at the highest level in the cambial region of the stem [16]. Stem growth in forest trees results from activity of the vascular cambium, as it does in cassava storage root formation. The cassava TCTP can have a functional role in vascular cambium, which plays a key role in storage root formation. Another gene that had increased transcription also in secondary xylem was the cassava protein homologue to calmodulin from Arabidopsis thaliana. Ours results show that the cassava calmodulin-like protein contains a conserved EF-Hand domain, which is a helix-loop-helix that binds $\mathrm{Ca}^{2+}$. Calmodulin mediates intracellular $\mathrm{Ca}^{2+}$ by regulating the activity/function of diverse proteins in a $\mathrm{Ca}^{2+}$-dependent manner. There is some evidence indicating the involvement of calcium and calmodulin in diverse cellular processes in plants including tuberization [17, 18]. In cassava this protein can play general functions in signal transduction mechanisms or cytoskeleton, cell division and chromosome partitioning.

Transcription of putative extensin protein was down regulated in cassava storage root (Figure 1). A similar result was observed in comparative analyses of storage root induction in sweet potato [12]. Extensins are proteins involved in diverse cellular processes, including cell wall formation. The significance of transcriptional down-regulation of this gene in secondary xylem of storage roots needs to be further examined. Putative MYB, 14,3,3- like and auxin regulated protein genes showed a same expression levels in adventitious and storage roots (Figure 1), indicating no change in gene expression pattern during storage organ formation.

\section{CONCLUSION}

In this study we identified potential cassava genes related to storage root formation that were transcriptionally regulated in secondary xylem tissues. The elucidation of the function of these differentially expressed genes in the cassava storage root was not the goal of the present study. However, these genes possibly play certain roles in the storage organ formation by regulating process, including 
decreasing of longitudinal growth of adventitious roots, initiation of secondary growth and signal transduction. Future experiments will focus on the isolation of genomic clones and in functional analysis.

\section{ACKNOWLEDGEMENTS}

We thank the Brazilian National Research Council (CNPq) and EMBRAPA-Genetic Resources and Biotechnology for fellowship grants. Thanks are also extended to Marco AV Agostini, who kindly prepared figure1 shown in this paper.

\section{REFERENCES}

[1] Puonti-Kaerlas, J. (1998) Biotechnology and Genetic Engineering Reviews, 15, 329-364.

[2] Cock, J.H. (1985) In: Cassava research, production and utilization (Cock, J.H. and Reyes, J.A., Eds). pp. 716-728. Centro Internacional de Agricultura Tropical, Cali, Colombia.

[3] Rateaver, B. (1951) in Anatomy and regeneration in the stem and root of Manihot utilissima Pohl. Ph.D. Thesis, University of Michigan, Ann Arbor, Michigan, USA.

[4] Castilloa, J.J., Castillo, A. and Pino, L.T. (1997) In La yuca frente al hambre del mundo tropical. pp. 77-100. Universidad Central de Venezuela, Caracas, Vanezuela.

[5] Cabral, G.B., Carvalho, L.J.C.B. and Schaal, B.A. (2000) in Cassava Biotechnology IVth International Scientific Meeting-CBN (Carvalho L.J.C.B., Thro A.M. and Vilarinhos A.D., Eds.), pp. 345-356, Embrapa-Recursos Geneticos e Biotecnologia, Brasilia-DF, Brazil.

[6] de Souza, C.R.B. (2001) In Isolamento e caracterização molecular de genes e proteínas de raiz de reserva de mandioca (Manihot esculenta Crantz), PhD thesis, Universidade de Brasília (DF), Brazil.

[7] Cabral, G.B. and Carvalho, L.J.C.B. (2001) Braz. J. Plant Physiol., 13, 41-48.

[8] de Souza, C.R.B., Carvalho, L.J.C.B., de Almeida, E.R.P., Gander, E.S. (2002) Plant Foods Hum. Nutr., 57 353-363.

[9] Carvalho, L.J.C.B., de Souza, C.R.B., de Almeida, E.R.P. (2002) In ASPB Plant Biology Meeting 2002, Denver, USA, abs. \#98.

[10] de Souza, C.R.B., de Almeida, E.R.P., Carvalho, L.J.C.B., Gander, E.S. (2003) Braz. J. Plant Physiol., $15,167-170$.

[11] Zhang, P., Bohl-Zenger, S., Puonti-Kaerlas, J., Potrykus, I., Gruíssem, W. (2003) Planta, 218, $192-$ 203.

[12] You, M.K., Hur, C.G., Ahn, Y.S., Suh, M.C., Jeong, B.C., Shin, J.S., Bae, J.M. (2003) FEBS Lett., 536, $101-105$

[13] Bommer, U-A. and Thiele, B-J. (2003) Int. J. Biochem. Cell. Biol., 36, 379-385.

[14] Gachet ,Y., Tournier, S., Lee, M., Lazaris-Karatzas, A., Poulton, T., Bommer, U.A. (1999) J. Cell Sci., 112, 1257-1271.

[15] Kim, M., Jung, Y., Lee, K. and Kim, C. (2000) Archives of Pharmacological Research, 23, 633-636.

[16] Sterky, F., Regan, S., Karlsson, J., Hertzberg, M., Rohde, A., Holmberg, A., Amini, B., Bhalerao, R., Larsson, M., Villarroel, R., Van Montagu, M., Sandberg, G., Olsson, O., Teeri, T.T., Boerjan, W., Gustafsson, P., Uhlen, M., Sundberg, B. L. (1998) Proc. Natl. Acad. Sci. USA, 95, 13330-13335.

[17] Poovaiah, B.W., Takezawa, D., An, G., Han, T.J. (1996) Plant Physiol., 149, 553-558.

[18] Reddy, A.S., Day, I.S., Narasimhulu, S.B., Safadi, F., Reddy, V.S., Golovkin M., Harnly, M.J. (2002) J. Biol. Chem., 277, 4206-4214.

Received on February 2, 2004, accepted on June 10, 2004. 